\title{
Eczema-Like Psoriasiform Skin Reaction due to Brazilian Keratin Treatment
}

\author{
Maria Fernanda Reis Gavazzoni-Dias ${ }^{\mathrm{a}}$ Mayra Rochael ${ }^{\mathrm{a}} \quad$ Enoï Vilar $^{\mathrm{a}}$ \\ Aline Tanus ${ }^{\mathrm{b}}$ Antonella Tosti ${ }^{\mathrm{c}}$ \\ a Universidade Federal Fluminense, Niterói, and ${ }^{b}$ Instituto de Dermatologia Professor Rubem David Azulay, \\ Rio de Janeiro, Brazil; ' Department of Dermatology and Cutaneous Surgery, University of Miami L. Miller School of \\ Medicine, Miami, Fla., USA
}

\section{Key Words}

Brazilian keratin treatment · BKT · Psoriasiform alopecia .

Drug reactions

\begin{abstract}
The use of formaldehyde and formaldehyde releasers in hairstraightening formulations started in Rio de Janeiro in 2003. The technique is known as BKT, Brazilian keratin treatment. The aim of this study was to analyze the types of skin reactions presented by patients due to BKT. We describe 7 patients with severe erythema and scurf on the scalp which developed shortly after BKT. The lesions were eczema-like psoriasiform, located mainly on the scalp. Some patients also developed eczema-like lesions and pustules on the face, neck, upper arms, and upper trunk. Dermatoscopic findings included erythema, perifollicular and interfollicular scurf. The peripilar desquamation resembled the outer skin of an onion bulb. Scalp biopsies revealed psoriasiform and spongiotic psoriasiform patterns, one of them similar to antiTNFa biologic drug psoriasiform alopecia. The possible consequences of the absorption of formaldehyde by hairdressers or clients are still to be verified by the scientific community; however, the skin and scalp reactions observed in our cases suggest a drug reaction phenomenon and not only eczemas of irritant or allergic origin.
\end{abstract}

(c) 2016 S. Karger AG, Basel

\section{Introduction}

The use of formaldehyde in hair-straightening formulations started in Rio de Janeiro, Brazil, in 2003 [1]. The technique is known as BKT, Brazilian keratin treatment, and, although not recommended by the Brazilian Health Surveillance Agency (ANVISA), it became very popular in Brazil, the USA, Latin America, and other countries [2]. The ingredients used today are not based on formaldehyde or glutaraldehyde but on formaldehyde releasers such as methylene glycol and glyoxylic acid. Both substances can release formaldehyde when heated such as during blow-drying and hot ironing [3-5]. Formaldehyde is not a hair-straightening substance. The hair becomes straight because water breaks the hydrogen bonds of the keratin molecule as happens during a regular blowdry. The newly redesigned keratin then keeps this shape because the formaldehyde crosslinks the keratin filaments in such a perfect alignment $[6,7]$.

The formaldehyde concentrations in BKT products, even those labeled as free of formaldehyde, may exceed recommended levels and serve as a health hazard. They may contain or release formaldehyde in up to 5 times

The study was conducted at the Instituto de Dermatologia Professor Rubem David Azulay, Rua Santa Luzia, Rio de Janeiro, Brazil.

\section{KARGER 125}

(c) 2016 S. Karger AG, Base

2296-9195/16/0013-0156\$39.50/0 
Table 1. Patients' data

\begin{tabular}{|c|c|c|c|c|}
\hline $\begin{array}{l}\text { Patient } \\
\text { No. }\end{array}$ & $\begin{array}{l}\text { Age, } \\
\text { years }\end{array}$ & $\begin{array}{l}\text { Onset of skin lesions, } \\
\text { days after BKT }\end{array}$ & Clinical findings & Dermatoscopic findings \\
\hline 1 & 22 & 7 & $\begin{array}{l}\text { psoriasiform patches on scalp, hair breakage, } \\
\text { enlargement of cervical lymph nodes, } \\
\text { erythematous scurfy patches with white thin } \\
\text { scurf on the neck and upper trunk, with small } \\
\text { scattered pustules }\end{array}$ & $\begin{array}{l}\text { perifollicular and } \\
\text { interfollicular erythema; } \\
\text { white silver thick scurf }\end{array}$ \\
\hline 3 & 31 & 7 & $\begin{array}{l}\text { erythematous scurfy patches on scalp and } \\
\text { erythema and scurfy lesions on face and } \\
\text { nape; the frontal area presented a violaceous } \\
\text { plaque with lichenification }\end{array}$ & $\begin{array}{l}\text { erythema; large lamellar } \\
\text { peripilar scurf resembling } \\
\text { the outer skin of an onion } \\
\text { bulb }\end{array}$ \\
\hline 5 & 15 & 1 & $\begin{array}{l}\text { erythematous patches with white psoriasiform } \\
\text { lamellar scurfy plaques distributed on scalp, } \\
\text { neck and postauricular }\end{array}$ & $\begin{array}{l}\text { erythema; peripilar } \\
\text { desquamation resembling } \\
\text { the outer skin of an onion } \\
\text { bulb; a few red dots }\end{array}$ \\
\hline 6 & 46 & 7 & $\begin{array}{l}\text { nonpruritic erythematous scurfy patches on } \\
\text { fronto-temporal hairline and pre-auricular }\end{array}$ & $\begin{array}{l}\text { erythema; perifollicular } \\
\text { and interfollicular scurf }\end{array}$ \\
\hline 7 & 50 & 10 & $\begin{array}{l}\text { pruritic erythematous scurf lesions on scalp, } \\
\text { face, neck, upper trunk, and arms }\end{array}$ & $\begin{array}{l}\text { erythema; perifollicular } \\
\text { and interfollicular scurf }\end{array}$ \\
\hline
\end{tabular}

higher concentrations than the recommended level [8]. In 2004, the International Agency for Research on Cancer (IARC) reclassified formaldehyde from a probable (Group 2A) to a known human carcinogen (Group 1). In 2012, the Committee for Risk Assessment of the European Chemicals Agency proposed a lower but still protective category, namely as a substance which is presumed to have carcinogenic potential for humans (Carc. 1B) [9].

Skin reactions developing after the use of BKT are assumed to be of contact allergic origin [10]. In our clinic, we observe many patients with a red scalp and skin and scurf due to BKT. So the aim of this study was to analyze and describe the types of skin reactions presented by these patients.

\section{Material and Methods}

We describe 7 patients with severe erythema and scurf on the scalp which developed shortly after BKT. The lesions were eczemalike and psoriasiform, located mainly on the scalp. Some patients also developed eczema-like lesions and pustules on the face, neck,
Table 2. Histopathological findings of the scalp biopsies performed in 4 patients

\begin{tabular}{lllll}
\hline & \multicolumn{2}{l}{ Patient No. } & & \\
\cline { 2 - 5 } & 1 & 2 & 3 & 5 \\
\hline Orthokeratosis & yes & yes & yes & no \\
Parakeratosis & yes & yes & yes & yes \\
Hypergranulosis & no & no & no & no \\
Hypogranulosis & yes & no & yes & yes \\
Psoriasiform acanthosis & yes & yes & yes & yes \\
\hline Espongiosis of the epidermis & no & yes & intense & no \\
Espongiosis of the follicle & yes & no & no & no \\
Dilated dermal blood vessels & yes & no & yes & yes \\
Suprapapillary thinning & no & no & yes & yes \\
Red cells extravasation & no & no & no & no \\
\hline Elevated number of & & & & \\
$\quad$ Neutrophils & yes & no & no & yes \\
\multicolumn{1}{l}{$\begin{array}{l}\text { Lymphocytes } \\
\text { Eosinophils }\end{array}$} & yes & yes & yes & yes \\
Plasma cells & yes & no & no & no \\
Necrotic keratinocytes & numerous & no & no & no \\
\hline
\end{tabular}


upper arms, and upper trunk. One patient developed cervical lymphadenopathy with no signs of infection. All patients were examined with a dermatoscope. Scalp biopsies were performed in 4 patients. None of the patients had a contact allergic test positive to formaldehyde, and none presented any allergies to nail polish. There was no evidence of bacteria or fungus infection in any of the patients observed.

The case reports are summarized in table 1 . Table 2 summarizes the histopathological findings. Images of clinical and dermatoscopic aspects are given in figure 1, and histopathological images are presented in figure 2 .

\section{Discussion}

Formaldehyde released from BKT may reach a patient's body by contact and/or inhalation. After a BKT, our patients presented with scalp lesions of psoriasiform nature, with erythema, lamellar scurf and skin lesions, with erythema and mild desquamation, and sometimes with sterile pustules. Lesions are normally nonpruritic, but one patient referred itching. The dermastoscopic features are similar to what is observed in seborrheic dermatitis, psoriasis and lichen planopilaris, but unlike those of contact dermatitis where there is no peripilar inflammation. The patients exhibited erythema, perifollicular and interfollicular scurf. The peripilar desquamation resembled the outer skin of an onion bulb. This aspect can be found on the scalp as well as on the facial lesions and may be a clue to the diagnosis.

The histopathology of the 4 scalp biopsies revealed psoriasiform dermatitis and spongiotic psoriasiform dermatitis, all compatible with drug reactions, due to contact or systemic absorption. Patient No. 1 presented a psoriasiform pattern very similar to what is described in cases of anti-TNFa scalp alopecia. According to Ackerman et al. [11], psoriasiform patterns form a major subset of perivascular dermatitis, which is the largest group of inflammatory skin diseases that may be associated with epidermal changes such as psoriasiform, interface/lichenoid, ballooning, or spongiotic patterns. Often, these changes are found in combination, and the components of this mixture give important clues to the correct diagnosis [11]. Psoriasiform dermatitis can be broadly classified as: psoriasiform only and combinations - psoriasiform lichenoid, spongiotic psoriasiform, and spongiotic psoriasiform lichenoid [12].

Psoriasiform features can appear in some dermatological skin diseases such as seborrheic dermatitis, contact dermatitis, erythroderma, mycosis fungoides, secondary syphilis, and pitiriasis rubra pilaris. Also, drug-related psorasiform lesions may develop from contact or systemic absorption, but they are not so common to happen [13]. Gulbahar et al. [14] described a case of psoriasiform dermatitis caused by topical propolis in a beekeeper. Vena et al. [15] described eczematous drug reactions due to systemic antihypertensive drugs. A histopathological diagnosis was available for 9 cases, confirming the presence of spongiotic dermatitis with possible associated psoriasiform skin changes with histopathological findings of spongiotic dermatitis [15].

While a single drug may cause a wide range of reaction patterns, no reaction pattern is specific for a certain drug. Nevertheless, some reactions are quite characteristic for certain drugs as for example psoriasiform dermatitis for anti-TNF agents or folliculitis for epidermal growth factor receptor antagonists [16]. Topical drugs usually cause irritant or allergic contact eczema. Allergic contact dermatitis may present typical clinical features but atypical forms such as lichenoid and psoriasiform allergic contact dermatitis may also be observed [17]. TNFa inhibitors (anti-TNFa biologic drugs), currently used to treat different autoimmune conditions, may be associated with cutaneous drug reactions. The onset of new or the worsening of existing psoriasis and psoriasis-like reactions has been reported in these patients.

Laga et al. [18] described the histopathological spectrum of psoriasiform skin reactions in 16 patients associated with TNFa inhibitor therapy. The work concluded that anti-TNF drugs elicit a spectrum of cutaneous reactions that go beyond the classical eosinophilic-rich hypersensitivity reaction and may closely mimic primary dermatitis including psoriasis-like lesions with subtle histopathological findings such as psoriasiform epidermal hyperplasia, neutrophils, eosinophils and plasm cells that varied depending on the patient. The authors also described lichenoid lesions and pustular folliculitis [18]. Osório et al. [19] described 5 cases of anti-TNFa-induced psoriasiform eruptions with severe scalp involvement.

Fig. 1. Clinical (a, c, e, g, i, k, m-p) and dermatoscopic (b, d, f, h, $\mathbf{j}, \mathbf{I})$ images of the patients. The dermatoscopic findings are similar to seborrheic dermatitis and psoriasis with exuberant peripilar scaling, resembling the outer skin of an onion bulb. All patients developed psoriasiform or eczema-like clinical lesions. The facial lesions also show the same perifollicular scaling (I, circles). Interfollicular erythema and scaling are also present, revealing that the inflammation is not only restrained to the hair follicle, but also involves the epidermis and the dermis $(\mathbf{b}, \mathbf{d}, \mathbf{f}, \mathbf{h}, \mathbf{j})$. Clinical lesions also affect skin areas where BKT has not been directly applied, such as the face, neck and upper trunk (m-p).

(For figure see next page.) 

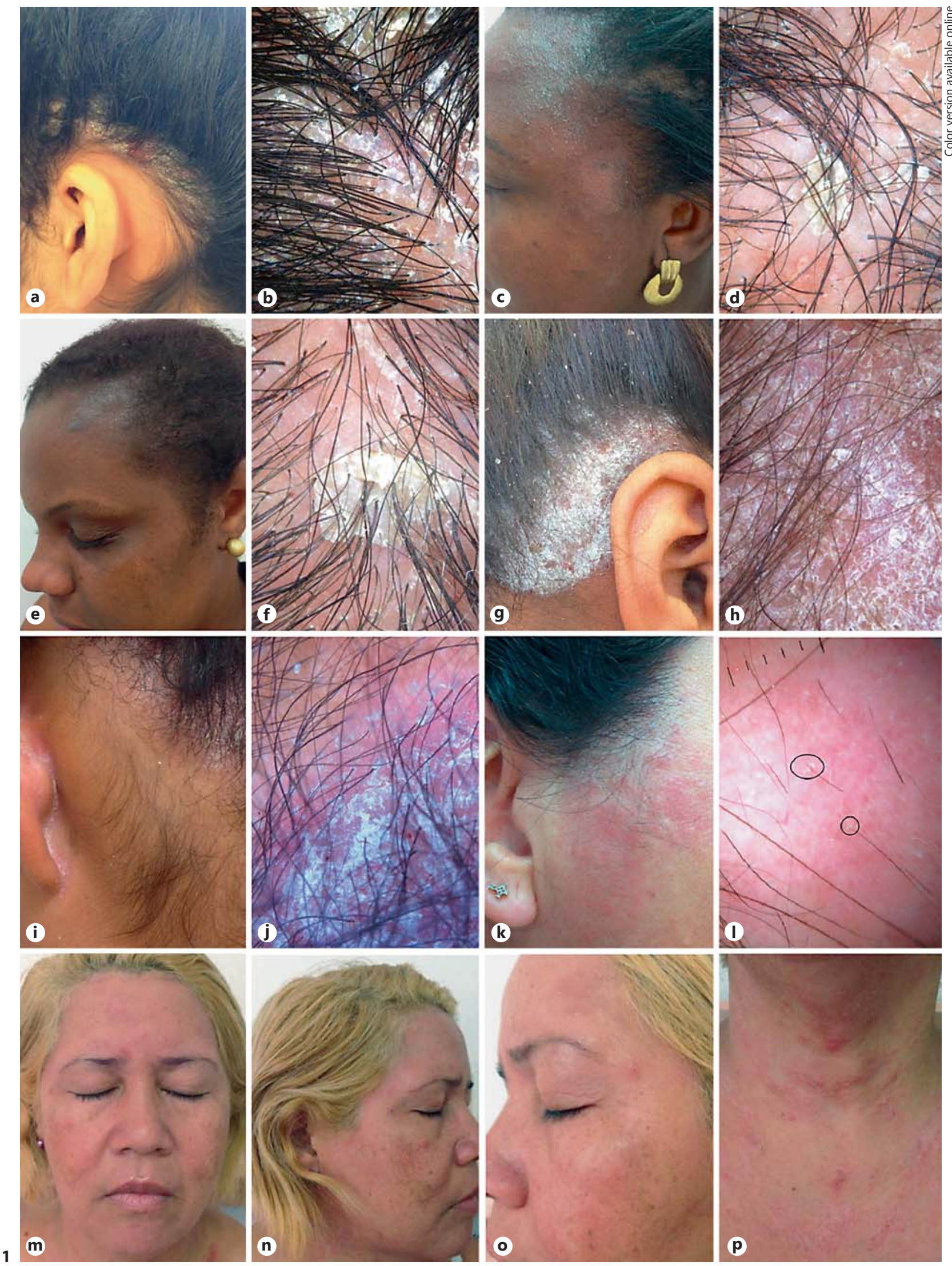
Fig. 2. Four biopsied patients showed psoriasiform or spongiotic psoriasiform dermatitis. a, b Orthokeratosis, parakeratosis, hypogranulosis, psoriasiform acanthosis, spongiosis of follicle, ectasia of dermal blood vessels, inflammatory infiltrate with neutrophils, lymphocytes, eosinophils and numerous plasma cells. c, d Orthokeratosis, parakeratosis, psoriasiform acanthosis with spongiosis of the epidermis. e, $\mathbf{f}$ Orthokeratosis, parakeratosis, hypogranulosis, psoriasiform acanthosis, intense spongiosis, suprapapillary thinning of the epidermis with dermal blood vessel ectasia. g, h Parakeratosis, hypogranulosis, suprapapillary thinning of the epidermis with dermal blood vessel ectasia, dermal inflammatory infiltrate with neutrophils.
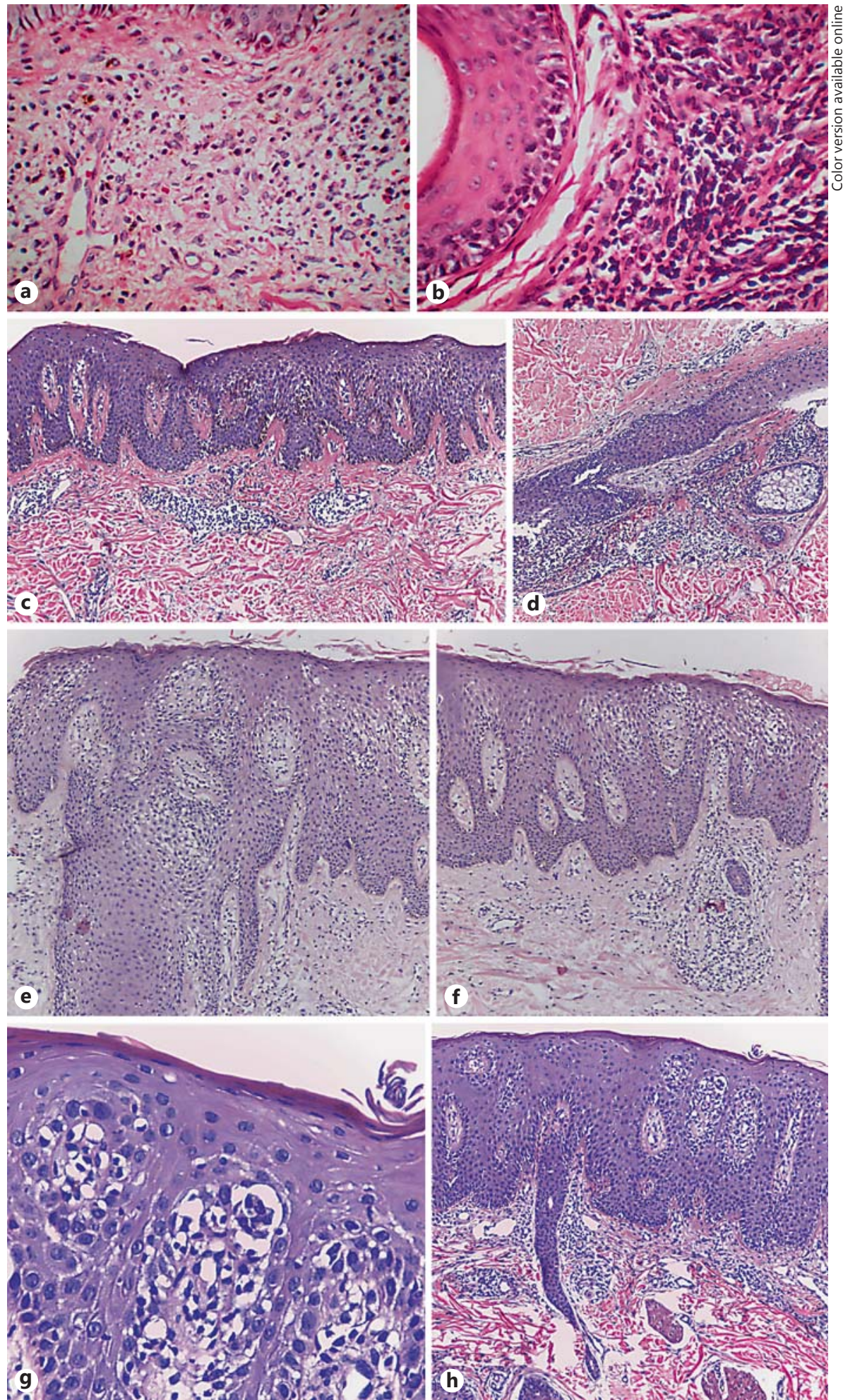
Doyle et al. [20] described 3 patients who developed psoriasiform lesions on the scalp after the use of anti-TNF drugs. The patients showed psoriasiform epidermal changes and alopecia areata-like dermal changes. The histopathology presented psoriasiform epidermal hyperplasia, espongiosis and parakeratosis with neutrophils. The dermal changes were due to a superficial lymphocytic inflammation with eosinophils and plasm cells. Some patients also developed psoriatic skin lesions in other parts of the body. According to the authors, the criteria for the diagnosis of anti-TNF-related alopecia are: a recent initiation of anti-TNF therapy, no prior history of psoriasis, a flare of psoriasis after starting the therapy, and alopecic patch(es) on the scalp and often on other parts of the body [20].

According to Tortola et al. [21], there is a central, unique and IL-1-independent role for IL-36 in the control of the IL-23/IL-17/IL-22 pathway and the development of psoriasiform dermatitis. Mabuchi et al. [22] concluded in their works that a subset of gamma delta $\mathrm{T}$ cells play a critical role in IL-23-mediated psoriasiform dermatitis. Still, the development of psoriasiform eruptions is to be better elucidated [22].

Tresch et al. [23] described a T-cell-mediated acute localized exanthematous pustulosis (ALEP) caused by finasteride that also bears histological resemblance with BKT scalp reactions and may share some of the same immunological background of inflammation. This unusual type of acute generalized exanthematous pustulosis (AGEP) presents histological features of psoriasiform acanthosis, spongiosis and infiltration of the epidermis and dermis by neutrophils and eosinophils. The authors suggest that this individual drug reaction may be related to different genetic factors, to the MHC molecules and to an increase in the number of TH17 cells and the levels of their produced cytokine IL-22. TH17 cells might augment the IL- 8 production by keratinocytes through the effects of IL-17 and IL-22, as described in AGEP [23]. Drug administration is the most frequent though not the sole cause of ALEP, and a plant contact was reported as the causative agent in the work of Mohamed et al. [24].

The precise pathophysiological mechanisms of AGEP and ALEP remain unknown. Previous studies in patients with AGEP have revealed a high rate of positive patch test responses and in vitro, lymphocyte-proliferative responses compared with other drug eruptions, suggesting that the reaction occurs due to a drug-specific, T-cell-mediated process [25]. All of our patients, though, presented negative patch tests to formaldehyde. It is of note that neutrophils are not so frequent and numerous in BKT scalp reactions as they are in AGEP and ALEP.

The causal mechanism behind the occurrence of psoriasiform anti-TNFa drug reactions is still a matter of debate, but it may implicate an imbalance of cytokines toward interferons, chemokines and probably IL-17, similar to what is thought to happen in ALEP [26].

BKT involves other substances beside formaldehyde, but it is most probable that formaldehyde is the drug responsible for the skin reactions. Over time, if exposed to air, formaldehyde reverts to a gas, its natural state at room temperature. When heated with a flat iron, formaldehyde vaporizes and this can explain the existence of skin lesions in areas where the product has not been directly applied, such as the face, neck and upper trunk. The exact history and evaluation of the clinical course are essential for the diagnosis of drug reactions mimicking dermatoses and present an important challenge for the clinician [26]. Subtle clues to drug reactions are: superficial dermal edema, activated lymphocytes, eosinophils and plasma cells, red cell extravasation, endothelial swelling vessels, exocytosis of lymphocytes, and apoptotic keratinocytes [27].

\section{Conclusions}

The possible consequences of the absorption of formaldehyde by hairdressers or clients are still to be verified by the scientific community; however, the skin and scalp reactions observed in our cases suggest a drug reaction phenomenon and not only eczemas of irritant or allergic origin. Psoriasiform skin reactions are related to several drugs, especially TNFa inhibitors, which may induce a typical psoriasiform epidermal hyperplasia with plasma cells and eosinophils, dermal infiltrate that may invade the hair follicle epithelium or other forms of psoriatic and lichenoid eruptions. Our patient No. 1 presented a typical anti-TNFa drug reaction. Patients No. 2, 3 and 4 showed a spongiotic psoriasiform pattern. The histopathology of the lesions also resembles ALEP, and it is possible that both entities have an analogous immunological basis with involvement of TH17 cytokines. The dermatoscopic findings included erythema, perifollicular and interfollicular scurf. The peripilar desquamation resembles the outer skin of an onion bulb. This aspect may be present on the scalp and on the facial lesions, and it may be a clue for the diagnosis. 


\section{Statement of Ethics}

The authors of this article state that the subjects in this work have given their informed consent and that the study protocol has been approved by the Instituto de Dermatologia Professor Rubem David Azulay's committee on human research.

\section{Disclosure Statement}

The authors declare no conflicts of interest..

\section{References}

1 ANVISA: Brazilian Health Surveillance Agency: Drug Market Regulation. http:// www.anvisa.gov.br/cosmeticos/legis/mercosul.htm (Accessed July 10, 2015).

2 Weathersby C, McMichael A: Brazilian keratin hair treatment: a review. J Cosmet Dermatol 2013;12:144-148.

3 Galiotte MP, Kohler P, Mussi G, Gattás GJ: Assessment of occupational genotoxic risk among Brazilian hairdressers. Ann Occup Hyg 2008;52:645-651.

4 Pierce JS, Abelmann A, Spicer LJ, et al: Characterization of formaldehyde exposure resulting from the use of four professional hair straightening products. J Occup Environ Hyg 2011;8:686-699.

5 National Toxicology Program: Final report on carcinogens background document for formaldehyde. Rep Carcinog Backgr Doc 2010;i-512.

6 Gavazzoni Dias MF: Hair cosmetics: an overview. Int J Trichology 2015;7:2-15.

7 Simpson WS, Crawshaw G: Wool: Science and Technology. Cambridge, Woodhead, 2002.

8 Maneli MH, Smith P, Khumalo NP: Elevated formaldehyde concentration in 'Brazilian keratin type' hair-straightening products: a cross-sectional study. J Am Acad Dermatol 2014;70:276-280.

9 IARC (International Agency for Research on Cancer): Formaldehyde, 2-butoxyethanol and 1-tert-butoxypropan-2-ol; in: IARC Monographs on the Evaluation of Carcinogenic Risks to Humans. Lyon, IARC, 2006, vol 88, pp 1-478.
10 Van Lerberghe L, Baeck M: A case of acute contact dermatitis induced by formaldehyde in hair-straightening products. Contact Dermatitis 2014;70:384-386.

11 Ackerman AB, Böer A, Bennin B, Gottlieb GJ: Histologic Diagnosis of Inflammatory Skin Diseases. An Algorithmic Method Based on Pattern Analysis, ed 3. New York, Ardor Scribendi, 2005.

12 Tirumalae R: Psoriasiform dermatoses: microscopic approach. Indian J Dermatol 2013; 58:290-293.

13 Justiniano H, Berlingeri-Ramos AC, Sánchez JL: Pattern analysis of drug-induced skin diseases. Am J Dermatopathol 2008;30:352-369.

14 Gulbahar O, Ozturk G, Erdem N, et al: A psoriasiform contact dermatitis due to propolis in a beekeeper. Ann Allergy Asthma Immunol 2005;94:509-511.

15 Vena GA, Cassano N, Coco V, De Simone C: Eczematous reactions due to angiotensinconverting enzyme inhibitors or angiotensin II receptor blockers. Immunopharmacol Immunotoxicol 2013;35:447-450.

16 Kerl K: Histopathological patterns indicative of distinctive adverse drug reactions. Chem Immunol Allergy 2012;97:61-78.

17 Lazarov A: Sensitization to acrylates is a common adverse reaction to artificial fingernails. J Eur Acad Dermatol Venereol 2007;21:169174.

18 Laga AC, Vleugels RA, Qureshi AA, et al: Histopathologic spectrum of psoriasiform skin reactions associated with tumor necrosis factor- $\alpha$ inhibitor therapy. A study of 16 biopsies. Am J Dermatopathol 2010;32:568-573.
19 Osório F, Magro F, Lisboa C, et al: Anti-TNFalpha induced psoriasiform eruptions with severe scalp involvement and alopecia: report of five cases and review of the literature. Dermatology 2012;225:163-167.

20 Doyle LA, Sperling LC, Baksh S, et al: Psoriatic alopecia/alopecia areata like reactions secondary to anti-tumor TNF alpha therapy: a novel cause of non-cicatricial alopecia. Am J Dermatopathol 2011;33:161-166.

21 Tortola L, Rosenwald E, Abel B, et al: Psoriasiform dermatitis is driven by IL-36-mediated DC-keratinocyte crosstalk. J Clin Invest 2012; 122:3965-3976.

22 Mabuchi T, Takekoshi T, Hwang S: Epidermal CCR6(+) gamma delta T cells are major producers of IL-22 and IL-17 in a murine model of psoriasiform dermatitis. J Immunol 2011;187:5026-5031.

23 Tresch S, Cozzio A, Kamarashev J, et al: T cellmediated acute localized exanthematous pustulosis caused by finasteride. J Allerg Clin Immunol 2012;129:589-594.

24 Mohamed M, Soua Y, Njim L, et al: Acute localized exanthematous pustulosis on the face: 6 cases in Tunisia. Ann Dermatol Venereol 2014;141:756-764.

25 Sim HS, Seol JE, Chun JS, et al: Acute localized exanthematous pustulosis on the face. Ann Dermatol 2011;23(suppl 3):S368-S370.

26 Magnolo N, Schwarz T, Ständer S: Cutaneous drug reactions imitating dermatoses. Hautarzt 2014;65:424-429.

27 Weedon D: Weedon's Skin Pathology, ed 3, No 1. London, Churchill Livingstone Elsevier, 2010, vol 2. 